\title{
Open reduction and internal fixation of acetabular fractures
}

\author{
G. Fica, M. Cordova, L. Guzman, D. Schweitzer \\ Hospital del Trabajador, Santiago, Chile
}

Accepted: 2 July 1998

Summary. Between 1982 and 1995, 84 patients with displaced acetabular fractures underwent open reduction and internal fixation in our institution. The mean follow-up was 5.5 years with a minimum of 2 years. There were 33 simple and 51 complex fractures according to the classification of Judet and Letournels. Reduction after operation was anatomical in $49 \%$ of the patients, satisfactory in $24 \%$, and unsatisfactory in 27\%. Using Merle d'Aubigné's scale, the clinical results were excellent in $39 \%$ of the patients, good in 29\%, fair in 8\%, and poor in $24 \%$. Factors of statistical significance associated with a poor clinical outcome were T-shaped fractures, unsatisfactory reduction (>3 $\mathrm{mm}$ residual displacement), age $>40$ years and development of avascular necrosis. Acetabular surgery is demanding, and a high rate of complications can be expected. Trauma centres should designate a group of surgeons who will consistently treat these fractures in order to obtain more experience and better results.

Résumé. Entre 1982 et 1995, 84 patients présentant des fractures déplacées de l'acétabulum ont eu une réduction ouverte avec fixation interne. Le suivi a été en moyenne de 5,5 ans avec des extrêmes de 2 à 13 ans. Selon la classification de Judet et Letournel, 33 fractures étaient simples (39\%) et 51 complexes (61\%). Après l'opération, la réduction était considérée anatomique dans $49 \%$ des cas, satisfaisante dans $24 \%$ et mauvaise dans 27\%. Avec l'échelle de Merle d'Aubigné, les résultats cliniques ont été excellents dans 39\% des cas, bons dans 29\%, médiocres dans $8 \%$ et mauvais dans $24 \%$. Les facteurs statistiquement significatifs des mauvais résultats ont été: les

Reprint requests to: D. Schweitzer, Hospital del Trabajador, Ramón Carnicer 185, Santiago, Chile, Tel.: 56-2-2221525; Fax: 56-2-2229564; e-mail: sofiam@ chilesat.net fractures en " $T$ ", la réduction non satisfaisante $(+d e$ $3 \mathrm{~mm}$ de déplacement résiduel) à l'âge de plus de 40 ans et la survenue d'une nécrose avasculaire. Le résultat de cette série confirme que la chirurgie acétabulaire est difficile et que le taux de complications peut être élevé. Il est recommandable de limiter à un groupe de chirurgiens le traitement opératoire de ces fractures afin d'obtenir une plus grande expérience et des meilleurs résultats.

\section{Introduction}

The treatment of displaced acetabular fractures has improved greatly over the last 30 years. Nonoperative management was preferred by most orthopedic surgeons until Judet et al. published their paper in 1964 [6] which led to a better understanding of the different types of acetabular fractures. The results reported by Letournel influenced surgeons around the world to choose open reduction and internal fixation for many of the displaced intraarticular fractures [7].

Articular fractures of the acetabulum require anatomic reduction, stable internal fixation, and early mobilization in order to obtain good functional results. Difficulties may be encountered because of the complex anatomy, difficult surgical approach, and other severe lesions which can delay open reduction.

Different reports [7-13] have shown good-to-excellent results in 70-90\% of patients following open reduction and internal fixation. Identification of prognostic factors in these injuries has always been a major concern, but there is no agreement on which of them are truly important in the final outcome.

The object of this study was to describe the clinical and radiological results of acetabular fractures treated by open reduction and internal fixation in our 
centre and to determine the prognostic factors which may influence the final outcome.

\section{Patients and methods}

Between 1982 and 1995, 84 patients with displaced acetabular fractures were operated on in our hospital by the same surgical team. There were 70 men and 14 women with a mean age of 35 years (15-75). The mean follow-up was 5.5 years with a minimum of 2 years. The cause of injury was a traffic accident in $74 \%$ of the patients. Associated lesions were present in 24 patients, 10 had unstable pelvic fractures, 7 had head injuries, and 7 had other extremity lesions. Plain radiographs of the pelvis, including Judet oblique views, were obtained for all patients, and in 42 cases (49\%) a CT scan was also performed. Fractures were then classified according to the system of Judet and Letournel [6]. There were $33(39 \%)$ simple fractures and $51(61 \%)$ were complex (Table 1$)$. Only 13 patients (15\%) sustained posterior dislocations of the hip and closed reduction was performed within $6 \mathrm{~h}$ of the accident.

The mean interval from injury to operation was 6.8 days (range 0-27). Indications for operative treatment included displacement greater than $3 \mathrm{~mm}$, unstable fracture dislocation of the hip, an intra-articular fragment, incongruency secondary to roof fracture, fracture of the femoral head and soft tissue interposition. The surgical approaches used were a Kocher-Langenbeck (KL) in $59(70 \%)$ patients, an extended iliofemoral in 12 (14\%), a KL and an ilioinguinal in 7 (8\%), an ilioinguinal alone in 4 and a triradiate in 2 patients. Postoperatively, early assisted active and passive motion was begun and nonweightbearing mobilisation was allowed as soon as possible. Antibiotic prophylaxis was used systematically in all patients for $48 \mathrm{~h}$, beginning $1 \mathrm{~h}$ before surgery. Eight patients were placed on low-dose heparin for deep venous prophylaxis. The quality of postoperative reduction and the long-term radiographic results were evaluated according to the Matta radiological system [8-10]. Anatomical reduction was defined as $0-1 \mathrm{~mm}$ of residual fracture displacement, satisfactory reduc- tion when displacement was $2-3 \mathrm{~mm}$ and unsatisfactory if the residual displacement was greater than $3 \mathrm{~mm}$. For clinical evaluation Merle D'Aubigné's scale [4], which mainly assesses pain, walking capability, and hip motion, was used in all patients.

\section{Results}

Following Matta's criteria, anatomical reduction was achieved in 41 patients (49\%). Twenty (24\%) had a satisfactory reduction and 23 patients $(27 \%)$ were unsatisfactory. One patient with an anterior column and posterior hemitransverse fracture who had an anatomical reduction of the fracture died of an unrelated cause 13 days after surgery. This patient was excluded from the overall assessment.

The clinical results at long-term follow-up in 83 patients were excellent in 32 (39\%), good in 24 (29\%), fair in 7 (8\%), and poor in 20 (24\%). Using the quality of the operative reduction as an assessment, the overall clinical outcomes were evaluated. Thirty-five of the 40 patients with anatomical reduction had excellent or good clinical results. Sixteen of the 20 patients with satisfactory reduction had excellent or good clinical results. None of the 23 patients with unsatisfactory reductions had an excellent clinical outcome, only 5 had good clinical results, and 15 were poor. Table 2 shows the relationship between the quality of the postoperative reduction and results.

Twenty-three (70\%) of the 33 patients with simple fractures had an excellent or good clinical outcome. Complex fractures had different clinical results depending on the fracture pattern. All patients with anterior column and posterior hemitransverse fractures
Table 1. Type of fracture and clinical outcome

Table 2. Joint reduction and clinical outcome

\begin{tabular}{|c|c|c|c|c|c|}
\hline Fracture type & Excellent & Good & Fair & Poor & Total \\
\hline Posterior wall & 12 & 4 & 1 & 4 & 21 \\
\hline Posterior column & 1 & 3 & - & 1 & 5 \\
\hline Anterior column & - & 3 & - & 1 & 4 \\
\hline Transverse & - & - & - & 3 & 3 \\
\hline $\begin{array}{l}\text { Anterior column+posterior } \\
\text { hemitransverse }\end{array}$ & 2 & 1 & - & - & $3^{\mathrm{a}}$ \\
\hline $\begin{array}{l}\text { Posterior column+posterior } \\
\quad \text { wall }\end{array}$ & 9 & 2 & - & 1 & 12 \\
\hline Transverse+posterior wall & 2 & 4 & 2 & 1 & 9 \\
\hline T-shaped & - & 2 & - & 6 & 8 \\
\hline Both columns & 6 & 5 & 4 & 3 & 18 \\
\hline
\end{tabular}

a A patient with an anterior column and a posterior hemitransverse fracture died of unrelated cause 13 days after surgery

\begin{tabular}{lccccl}
\hline Adequacy of reduction & Excellent & Good & Fair & Poor & Total \\
\hline Anatomic $(0-1 \mathrm{~mm})$ & 29 & 6 & 1 & 4 & $40^{\mathrm{a}}$ \\
Satisfactory $(2-3 \mathrm{~mm})$ & 3 & 13 & 3 & 1 & 20 \\
Unsatisfactory $(>3 \mathrm{~mm})$ & - & 5 & 3 & 15 & 23 \\
\hline
\end{tabular}

a A patient with an anterior column and posterior hemitransverse fracture with anatomical reduction. Died of unrelated cause 13 days after surgery 

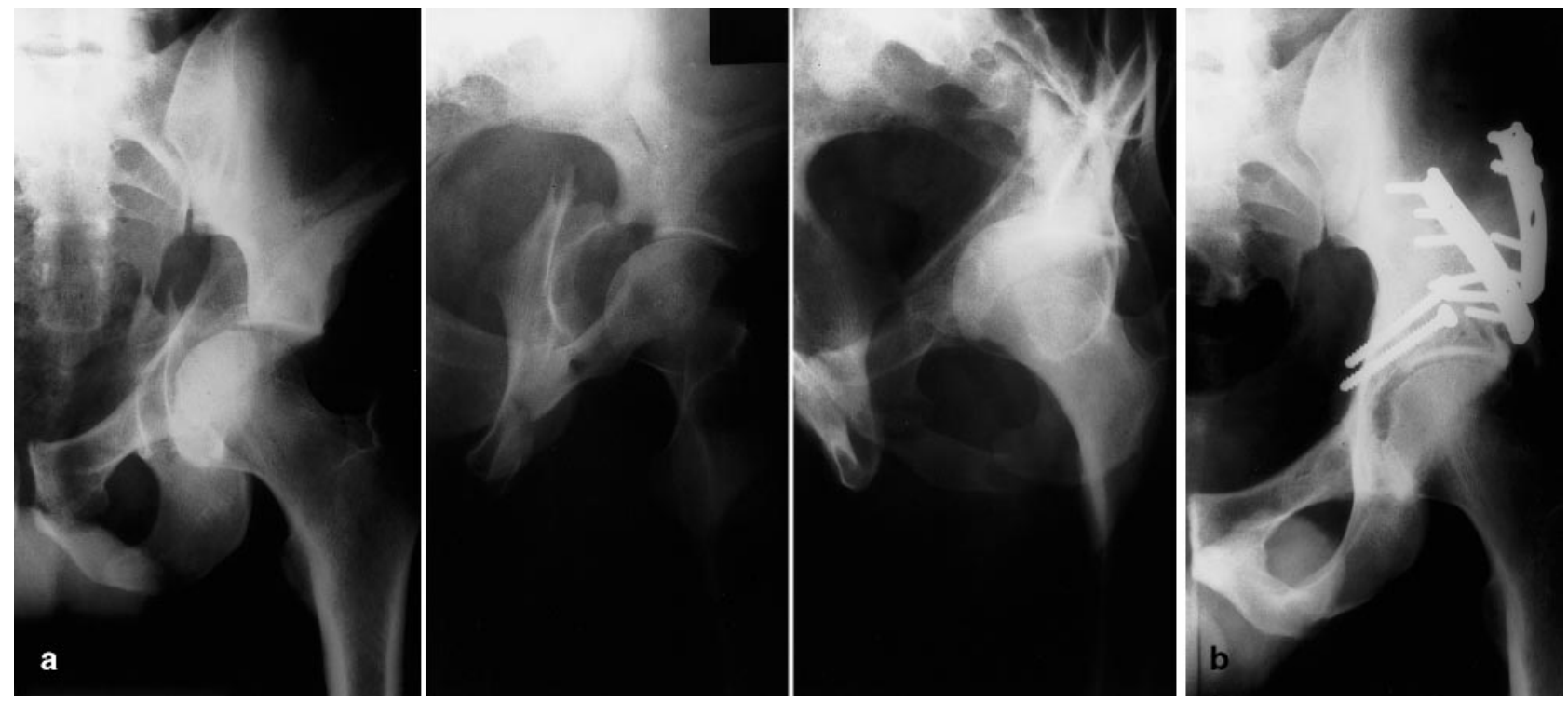

Fig. 1. a Anteroposterior and oblique views of a both column fracture. b Antero-posterior radiograph 4 years after surgery. The joint space is normal with marginal heterotopic ossification

Table 3. Age and clinical outcome

\begin{tabular}{lccccc}
\hline Age & Excellent & Good & Fair & Poor & Total \\
\hline <40 years & 26 & 16 & 4 & 6 & 52 \\
>40 years & 6 & 8 & 3 & 14 & 31 \\
\hline
\end{tabular}

had excellent or good results. Eleven (92\%) of the 12 patients with posterior column and posterior wall fractures had excellent or good results. Six $(67 \%)$ of the 9 patients with transverse and posterior wall fractures had excellent or good results. Only 2 of the 8 patients with T-shaped fractures had good results, whereas $6(75 \%)$ had a poor outcome. Eleven (61\%) of the 18 patients with fractures of both columns had excellent or good results (Fig. 1) and the remaining seven $(39 \%)$ had a regular or poor clinical outcome (Table 1).

Thirty-one patients were $>40$ years of age; the clinical outcome was excellent or good in 14 patients $(45 \%)$ and regular or poor in $17(55 \%)$. Fifty-two patients were $\leq 40$ years of age; the clinical results were excellent or good in 42 patients $(81 \%)$ and regular or poor in $10(19 \%)$ (Table 3$)$.

Patients were assessed according to the length of time from injury to operative stabilization of the fracture. Forty-eight patients underwent surgery $\leq 7$ days after injury, with excellent or good clinical results in $31(65 \%) ; 35$ had surgery $>7$ days after injury with excellent or good results in 25 patients $(71 \%)$.

Heterotopic ossification developed in 13 patients (16\%), 10 had Brooker's grade I and II (8 KL and 2 iliofemoral approaches), 2 had Brooker's grade III (triradiate approach) and 1 had Brooker's grade IV (KL approach). This patient underwent resection of the ossification and indomethacin therapy for 4 weeks.
The overall rate of major postoperative complication was $22 \%$, with ten neurological lesions (12\%), four infections $(5 \%)$, one re-displacement, one femoral vein thrombosis, two hematomas and one intra-articular screw placement. The neurological lesions were eight sciatic nerve palsies, one femoral nerve palsy and one superior gluteal nerve palsy. All recovered spontaneously within a year except for the gluteal nerve injury and one sciatic nerve palsy. Out of the four infections, two superficial, one resulted in septic arthritis of the hip in a patient who also had an open fracture of the pelvis with sepsis. The patient with redisplacement was left untreated. The patient with deep vein thrombosis received anticoagulant therapy for a period of 6 months and the hematomas were drained surgically. The intra-articular screw was discovered on a CT scan 4 months after surgery and was then removed. Eight patients (10\%) developed avascular necrosis at follow-up and were treated according to the severity of their symptoms.

Twelve patients (14\%) had undergone total hip arthroplasty at the time of the review. All who required reoperation, including total hip arthroplasty, were considered as having a poor clinical result.

\section{Discussion}

Our clinical results using the Merle D'Aubigné scale were good to excellent in $68 \%$ of our patients. These results are slightly lower than the $80 \%$ of excellent or good results reported by Letournel [7] and Matta [8-10], and are similar to the series published by Mayo [12], who had $75 \%$ satisfactory results. Wright et al. [14] noted that a 1-year follow-up is not adequate when evaluating the outcome of fractures involving weightbearing articular surfaces and there- 
fore recommended at least 2 year's follow-up. Their good-to-excellent results with a minimum of 2 years follow-up using the Harris hip score were lower $(45 \%)$ than in our series.

Many factors have been studied to determine their role in the prognosis of acetabular fractures treated by open reduction and internal fixation. A strong correlation between adequate operative reduction and satisfactory clinical outcome has been reported [7, 9]. In this study $88 \%$ of the patients with anatomical reduction had an excellent or good clinical outcome compared to only $22 \%$ of good clinical results in those patients with unsatisfactory reductions $(P<0.05)$. These results confirm that one of the most important goals in the surgical treatment of acetabular fractures must be the anatomical reduction of the joint surface.

The results according to the fracture type based on Letournel's classification into simple and complex were similar. Seventy percent of the patients with a simple fracture pattern had excellent or good clinical results, compared to $66 \%$ in patients with a complex pattern. All three patients with a transverse fracture obtained a poor clinical result, but all also had an unsatisfactory reduction, and therefore these poor results cannot be attributed to the type of fracture. Not all complex fracture types had the same outcome, Tshaped fractures having the worst clinical outcome.

There is no general agreement as to the influence of age at the time of injury [5, 14]. In our study patients over 40 years of age had the worst clinical outcome $(P<0.05)$.

There were only 13 patients with posterior dislocation of the hip in our series, and we did not classify protrusion of the femoral head into the pelvis as a central dislocation. Wright et al. [14] found a significant difference in results between patients with and without dislocation at the time of injury, but did not specify results according to the type of dislocation, central or posterior. In our study $77 \%$ of the patients with acetabular fracture and posterior hip dislocation had obtained excellent or good clinical results at follow-up.

It is generally agreed that the optimal time for stabilization of acetabular fractures is within the first week, but many other factors such as the general condition of the patient, skin and soft tissue damage, or associated orthopedic injuries can delay operation. However, we found no difference in the final clinical outcome between patients who underwent surgery $\leq 7$ days after injury and those who were operated on $>7$ days after.

Heterotopic ossification is common after surgery for acetabular fractures and the overall incidence is reported to be from 18 to $90 \%[2,3]$. There is also a clear relation between Brooker class III and IV heterotopic ossification and poor clinical results. Surprisingly, in our series only $16 \%$ of the patients developed heterotopic ossification. Only two patients received prophylactic treatment with indomethacin. We have no explanation for this difference with other reports. Avascular necrosis (AVN) is a severe complication which leads to poor functional results. In our study eight patients $(10 \%)$ developed AVN; five have already undergone total hip arthroplasty and one patient an arthrodesis. This is slightly higher than the rates reported in other series [7, 11, 14]. There was no correlation between hip dislocation and AVN, and no patient with AVN had an acceptable clinical result.

Iatrogenic nerve injury is the most frequent complication as a result of surgery, ranging from 2 to $18 \%[1,5,7]$. Baumgaertner et al. [1] advocated the use of cortical somatosensory-evoked potentials intraoperatively to reduce iatrogenic sciatic nerve injuries. Most of the nerve injuries in our study were in the earlier cases treated. CT scans are helpful in preoperative planning, giving information about the medial wall and intra-articular fragments.

If the principles of interpreting and managing acetabular fractures developed by Judet and Letournel are followed, satisfactory results can be obtained. Acetabular fractures should be treated by surgeons with a special interest and expertise in their management.

\section{References}

1. Baumgaertner MR, Wegner D, Booke J (1994) SSEP monitoring during pelvic and acetabular fracture surgery. J Orthop Trauma 8:127-133

2. Berton RM, Letournel E (1994) Low-dose irradiation and indomethacin preven heterotopic ossification after acetabular fracture surgery. J Bone Joint Surg [Br] 76:895-900

3. Brooker AF, Bowerman JW, Robinson RA, Riley LH (1973) Ectopic ossification following total hip replacement. J Bone Joint Surg [Am] 55:1629-1632

4. Merle D'Aubigné R, Postel M (1954) Functional results of hip arthroplasty with acrylic prosthesis. J Bone Joint Surg [Am] 36:451-460

5. Helfet DL, Borrelli J, Jr, DiPasquale T, Sanders R (1992) Stabilization of acetabular fractures in elderly patients. J Bone Joint Surg [Am] 74:753-765

6. Judet R, Judet J, Letournel E (1964) Fractures of the acetabulum: classification and surgical approaches for open reduction. J Bone Joint Surg [Am] 46:1615-1646

7. Letournel E (1981) Fractures of the acetabulum. Springer, Berlin Heidelberg New York

8. Matta JM (1994) Operative treatment of acetabular fractures through the ilioinguinal approach. A ten years' perspective. Clin Orthop 305:10-19

9. Matta JM, Mehne DK, Roff R (1986) Fractures of the acetabulum: early results of a prospective study. Clin Orthop 205:241-250

10. Matta JM, Merritt PO (1988) Displaced acetabular fractures. Clin Orthop 230:80-97

11. Mayo K (1993) Fractures of the acetabulum. Orthop Clin North Am 18:43-57

12. Mayo K (1994) Open reduction and internal fixation of fractures of the acetabulum. Results in 163 fractures. Clin Orthop 305:31-37

13. Oransky M, Sanquinetti C (1993) Surgical treatment of displaced acetabular fractures: results of 50 consecutive cases. J Orthop Trauma 7:28-32

14. Wright R, Barrett K, Christie MJ, Johnson KD (1994) Acetabular fractures: Long term follow-up of reduction and internal fixation. J Orthop Trauma 8:397-403 